Brit. Heart F., 1967, 29, 577.

\title{
Six Cases of Congenital Complete Heart Block Followed for 34-40 Years
}

\author{
MAURICE CAMPBELL AND RICHARD EMANUEL
}

\author{
From the National Heart Hospital, London W.1, and Guy's Hospital, London S.E.1
}

This paper describes the progress of six patients with congenital complete heart block, who are now (1966) between 47 and 67 years of age and have been followed intermittently for between 34 and 40 years. The inquiries now being carried out on 244 children with congenital heart block, 136 of them with this as the only malformation, by Michaèlsson of Uppsala and Swiderski of Warsaw, on behalf of the European Society of Pædiatric Cardiologists, will give a much broader view of its natural history. It will, however, need a generation before they can cover this aspect of long survival.

In 1934, Campbell and Suzman reported 8 patients with congenital complete heart block. Six of them were leading relatively normal lives, and two, both with other cardiac abnormalities, died when 5 years old, Case 6 before and Case 1 just after that paper was written.

The subsequent progress of the 6 survivors and of one additional patient (Case 9) was reported by Campbell (1943a) when their ages were between 22 and 43 years; and by Campbell and Thorne in 1956. Case 9 was fully reported then, since he had died in 1955 at the age of 49 . Five were getting on very well, though Case 5 had developed essential hypertension at the age of 56; the sixth (Case 8) was the only patient with significant symptoms (see later).

This paper describes the progress of these six patients with their original case numbers to make comparison easy. Because they were all seen in the years 1926-32, we thought the condition must be much more common than is supposed, but subsequent experience has not borne this out. Zoob and Shirley Smith (1963) included only one man as congenital among their 51 cases of complete heart block and most authors have not included any. Among

Received October 26, 1966. the many patients with cardiac malformations who were seen by one of us in 1948-54 there were, however, 8 who had heart block in addition, sometimes perhaps congenital. They were reported by Campbell and Thorne and their subsequent progress is described later in this paper. It has been much less satisfactory than the progress of the 6 who presented as complete heart block.

In 1934, we were unduly influenced by the view, widely held then and for some time after (White, 1951), that a ventricular septal defect was present in most cases with congenital complete heart block. We therefore interpreted the soft systolic murmur as evidence of this in our patients. But in 1956, with a greater knowledge of this diagnosis, we gave full reasons for thinking that none of them had a ventricular septal defect. The systolic murmurs, when present, were and still are soft, and none had or have a systolic thrill or signs of an increased pulmonary blood flow on radioscopy, so this is still our general view.

Case 8 is an exception. By the age of 32 (1948) he had developed a large heart, left bundle-branch block, and some aortic regurgitation, then attributed to the presence of a bicuspid aortic valve. Recently (1965) he was admitted to Guy's Hospital with left ventricular failure. A retrograde aortogram and left ventricular angiocardiogram showed that he had corrected transposition of the great trunks, a ventricular septal defect, and mitral regurgitation, in addition to his aortic regurgitation. For the last year or so he has been losing ground and has congestive heart failure that still needs treatment.

\section{Evidence that the Heart Block is CONGENITAL}

The main evidence for this is the early age at which the slow heart rate is observed and the ab- 
sence of any history of rheumatic fever or diphtheria or of any other infections that might have been the cause.

The slow heart rate was observed in the first 2 years of life in four (Table I), at 5 years in Case 7, and "when a small child" in Case 9 by our late colleague at the National Heart Hospital, Dr. R. O. Moon. It was not found till the age of 13 in Case 8, but the congenital ætiology of his heart block is made more certain by the other malformations of the heart reported above.

Electrocardiographs were not in common use in England when these patients were born, but were taken when we first saw them to confirm the diagnosis of complete heart block. This was at the age of 12 or 13 in four of them, at 20 years in Case 7, at 27 in Case 5, and at 29 in Case 9, though there had been comment, generally several independent comments, on their slow heart rates long before this.
There has been very little change in the cardiograms (Fig. 1 and 2) except in Cases 7 and 8.

\section{General Picture of these Patients}

The lives they have led could, we think, be taken as representative of the general population. Three of the boys took up games with enthusiasm as soon as they were allowed to, and continued their athletic activities through their twenties. One of these (Case 3) carried out all his duties in the wartime R.A.F. and was passed as fit for flying. The other two (Cases 4 and 8) led unusually active lives, one with very heavy work, till well in their thirties. After this they settled into more ordinary jobs as an electrician, an engineer, and in a tobacconist and newsagent's shop with very long hours. The fourth man (Case 9) led an ordinary professional life and added golf and gardening until shortly be-

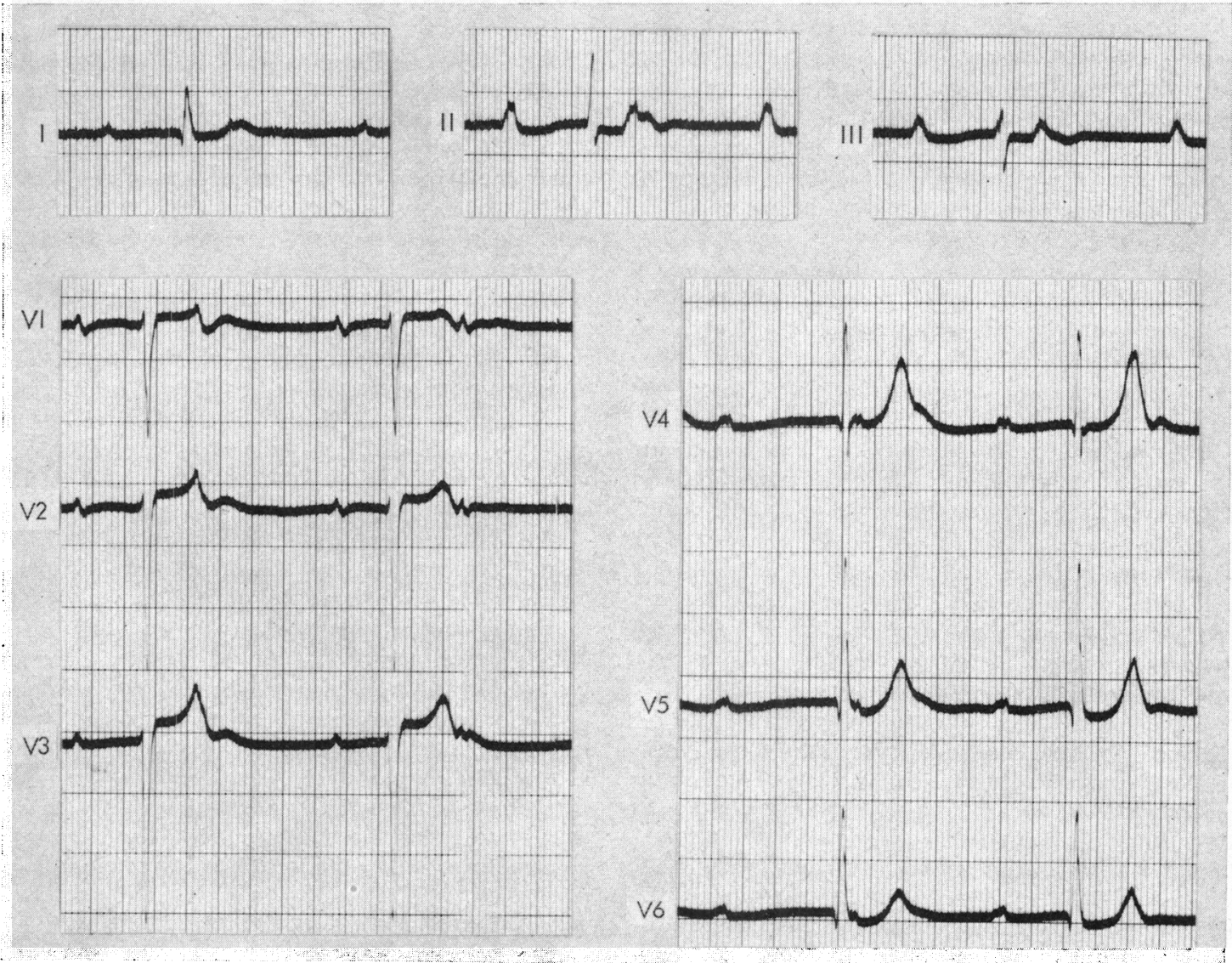

FIG. 2.-Case 4. Above, leads I, II, and II. Below, leads V1-V6 (all 1966). The rates are changing slightly. Thus, the ventricular rate is just under 40 in V1 and under 42 a minute in V4, while the atrial rates are 75 in $\mathrm{V} 1$ and 71 , in V4. The ventricular rate was more often about 50 a minute. 
TABLE I

AGE AND SEX OF OUR PATIENTS AND THEIR BLOOD PRESSURE

\begin{tabular}{|c|c|c|c|c|c|c|c|c|c|c|}
\hline \multirow{3}{*}{\multicolumn{2}{|c|}{$\begin{array}{l}\text { Case No. and } \\
\text { sex }\end{array}$}} & \multicolumn{3}{|c|}{ Age (yr.) } & \multicolumn{6}{|c|}{ Systolic and diastolic blood pressure $(\mathrm{mm} . \mathbf{H g})$} \\
\hline & & \multirow{2}{*}{$\begin{array}{l}\text { When slow } \\
\text { pulse first } \\
\text { discovered }\end{array}$} & \multirow{2}{*}{$\begin{array}{l}\text { When first } \\
\text { proved by } \\
\text { electro- } \\
\text { cardiogram }\end{array}$} & \multirow{2}{*}{$\begin{array}{l}\text { At present } \\
\text { (1966) }\end{array}$} & \multicolumn{2}{|c|}{1933} & \multicolumn{2}{|c|}{1954} & \multicolumn{2}{|c|}{$1965-66$} \\
\hline & & & & & Syst. & Diast. & Syst. & Diast. & Syst. & Diast. \\
\hline $\begin{array}{l}2^{\star} \\
3 \\
4 \\
5 \\
7 \\
8 \\
9\end{array}$ & $\begin{array}{l}\mathbf{F} \\
\mathbf{M} \\
\mathbf{M} \\
\mathbf{F} \\
\mathbf{F} \\
\mathbf{M} \\
\mathbf{M}\end{array}$ & $\begin{array}{c}1 \\
2 \\
2 \\
2 \\
5 \\
13 \\
\text { As a young } \\
\text { child }\end{array}$ & $\begin{array}{l}12 \\
12 \\
12 \\
27 \\
20 \\
13 \\
29\end{array}$ & $\begin{array}{l}52 \\
47 \\
50 \\
67 \\
54 \\
50 \\
49+\end{array}$ & $\begin{array}{l}160 \\
120 \\
120 \\
190 \\
150 \\
130 \\
125\end{array}$ & $\begin{array}{l}80 \\
65 \\
50 \\
90 \\
90 \\
70 \\
80 \dagger\end{array}$ & $\begin{array}{l}150 \\
105 \\
140 \\
260 \\
135 \\
160 \\
150\end{array}$ & $\begin{array}{r}70 \\
65 \\
80 \\
120 \\
85 \\
90 \\
85\end{array}$ & $\begin{array}{l}150 \\
120 \\
170 \\
\frac{130}{165} \\
-\end{array}$ & $\begin{array}{l}75 \\
60 \\
80 \\
85 \\
90 \\
\end{array}$ \\
\hline \multicolumn{2}{|c|}{ Means } & $4-5$ & 18 & 53 & $\begin{array}{l}142 \\
134 \ddagger\end{array}$ & $\begin{array}{l}75 \\
72 \cdot 5 \ddagger\end{array}$ & $\begin{array}{l}157 \\
140 \ddagger\end{array}$ & $\begin{array}{l}85 \\
79 \ddagger\end{array}$ & $147 \ddagger$ & $78 \ddagger$ \\
\hline
\end{tabular}

* Cases 1 and 6 died about 1934.

t Age at death in 1955: his blood pressure was first recorded in 1935.

Excluding Case 5.
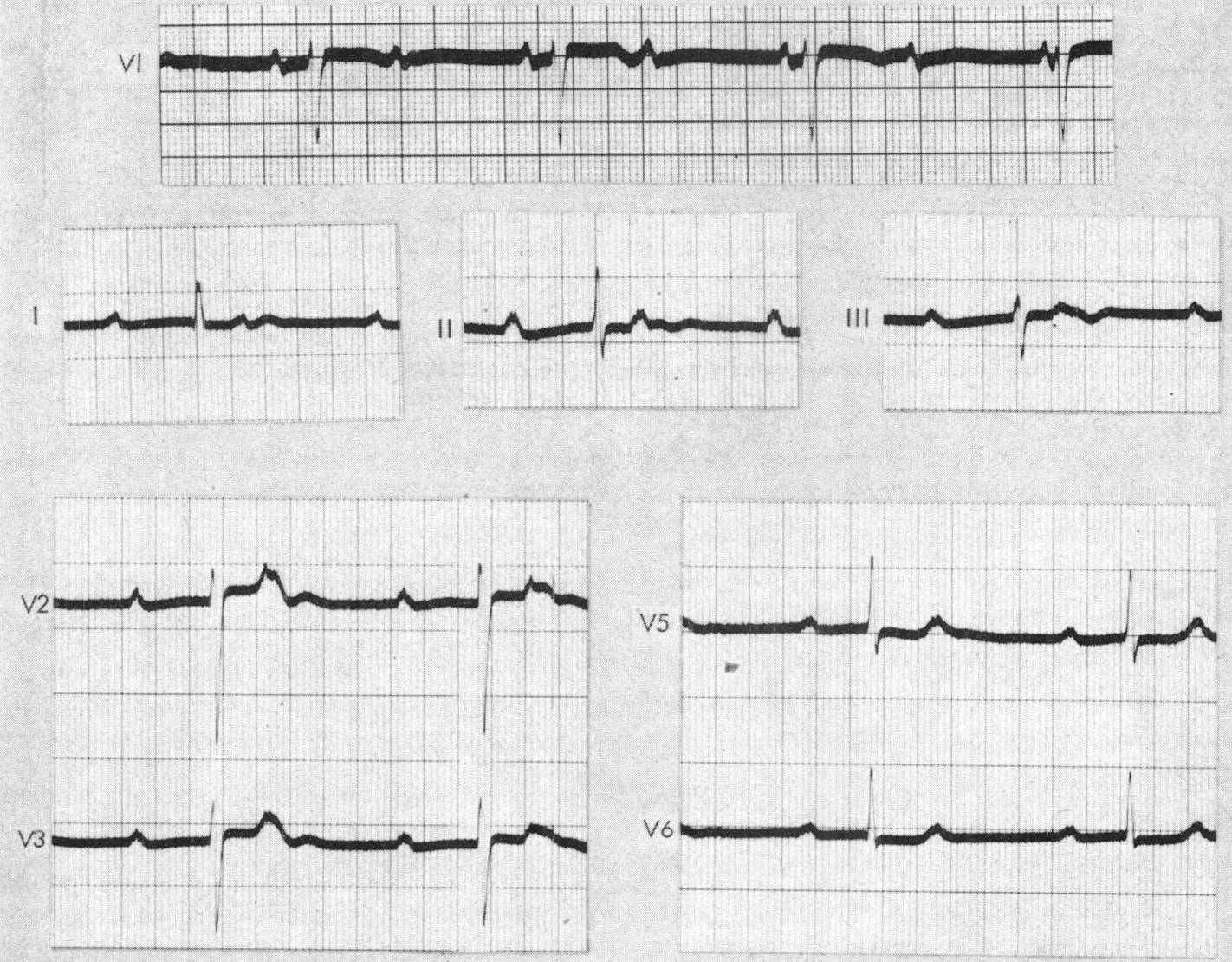

Fig. 1.-Case 2. Above, a run of V1 (taken in 1960) to show the complete heart block more clearly: atrial, 81 ; ventricular, 42 a minute. This is now about her usual ventricular rate, but it was faster in 1933-54. In middle, standard leads; and below, leads V2, V3, V5, and V6 (1965). The atrial rate was about 77 and the ventricular rate was 39 a minute. 
fore his death in 1955. He is included with our 6 surviving patients where pertinent.

Two of the girls (Cases 2 and 7) were not allowed to play games at school and perhaps because of this have led rather quiet but normal lives. The former is married but was advised not to have children (probably because she had tuberculosis). The third woman (Case 5) has spent her life in the country. Till she was 30 , she cycled long distances and did the hard outdoor work of a farm, but afterwards she worked inside. In her fifties she was found to have essential hypertension (BP 260/120 $\mathrm{mm}$. $\mathrm{Hg}$ ) but still manages to run her home at the age of 67 . She is, we think, the oldest reported case of congenital complete heart block.

Stokes-Adams Attacks. These are not uncommon in infants and young children with congenital complete heart block, and are the main cause of death in those who are free from other malformations of the heart. Only Case 4 among our 6 surviving patients has ever had a Stokes-Adams attack, and he is unusual in his recovery from frequent attacks between the ages of 2 and 4 years and in their rare recurrences from time to time for nearly 50 years. This is not easy to understand but on some occasions they seem to have been provoked by his doing too much. To save repetition, the details about these attacks, and about the change from complete to partial heart block in Case 7, are described with the Case Notes (see later).

Disappearance of complete heart block was observed in one case only. So far as we can tell, Case 7 always had complete heart block till the age of 35 . After this she was not seen for 7 years when she was asked to attend hospital for review. We were surprised to find that her heart block had changed from being complete to latent (Campbell, 1943c) with sinus rhythm generally between 70 and 90 and a $P-R$ interval of 0.44 sec.

From this time, when she was 42 , till the age of 54 she seems to have continued with latent heart block with $P-R$ intervals between 0.48 and 0.32 sec. without any dropped beats being observed. This variability of conduction time is not uncommon. Mathewson and Brereton (1964) reported an interesting 15-20 year follow-up of 95 men with atrioventricular heart block, mostly with latent but some with higher degrees of block. They found that all but 6 of their patients showed fairly wide variation in the length of the P-R interval, e.g. as wide as between 0.48 and 0.21 sec. and between 0.44 and $0.32 \mathrm{sec}$. in two of those with longer P-R intervals.

The absence of dropped beats in our Case 7 might perhaps be expected, since these were found to be due to a transient infection or to treatment with digitalis in two-thirds of 29 cases of latent heart block with dropped beats (Campbell, 1942, 1943b). Even so, a P-R interval of 0.48 sec. is unusually long. Among 141 cases with latent heart block without dropped beats, Campbell (1943c) found the longest in a young woman with mitral stenosis: for several years it was always between 0.36 and $0.40 \mathrm{sec}$. The two with longer P-R intervals than this, 0.47 and $0.56 \mathrm{sec}$., both had dropped beats, the former having rheumatic pericarditis and the latter probably tuberculous pericarditis.

\section{Heart Rate, Heart Size, and Blood PRESSURE}

Heart Rate at Rest. When we first saw these patients between the ages of 12 and 29, the mean heart rate was 48 a minute, and the mean of the individual ranges 43 to 53 . Taking single observations from any patient, the extreme range at rest was from 36 to 64 a minute.

In 53 collected cases of congenital complete heart block, Campbell and Suzman (1934) found the rate was between 30 and 60 a minute in threequarters, and between 40 and 54 in over 60 per cent. The rate in acquired complete heart block is generally slower than this. Campbell (1944) found it was generally between 28 and 40 and Wood (1956) gives its usual rate as between 28 and 36 a minute. The relatively fast rate of congenital heart block may be one reason why it is often missed. For example, Case 9 remembered being demonstrated as an example of sinus bradycardia due to jaundice, for which he had been admitted to Guy's Hospital while he was a dental student.

We thought that, as many of the patients were children, the heart rates might become slower and nearer to those of acquired heart block as they grew older. We found no evidence that this was so in 1955 when their average age was 39 years. The mean rate had not changed significantly, 47 instead of 48 a minute, with a very similar range (Table II).

Now, after another decade, it seems as if there is some slowing. There are five cases where we can make a comparison at each period of observation. The mean rate has fallen a little, from 48 to 43 a minute, still rather faster than in most acquired cases. In two, there has been no change, though in 1955 the rate had become slower in Case 3 and faster in Case 5. In the other three, the average fall is rather more, from 50 to 40 a minute. Two of these showed no fall of the rate in 1955, but the third had fallen half way by then. The numbers are hardly enough to be sure of this slowing of the 
TABLE II

CHANGES IN HEART RATE AND HEART SIZE

\begin{tabular}{|c|c|c|c|c|c|c|c|c|c|c|}
\hline \multirow{2}{*}{\multicolumn{2}{|c|}{ Case No. and Sex }} & \multicolumn{6}{|c|}{ Heart rate at rest } & \multicolumn{3}{|c|}{ Heart size } \\
\hline & & \multicolumn{2}{|c|}{$\mathrm{A}^{1932-33} \mathrm{~V}$} & \multicolumn{2}{|c|}{ A ${ }^{1954} \mathrm{~V}$} & \multicolumn{2}{|c|}{$A^{1966} \mathrm{~V}$} & \multirow{2}{*}{$\begin{array}{c}1933 \\
\\
55 \\
52 \\
(+) \\
+ \\
50 \\
49\end{array}$} & \multirow{2}{*}{$\begin{array}{c}1954 \\
50 \\
46 \\
45 \\
++ \\
46 \\
56\end{array}$} & \multirow{2}{*}{$\begin{array}{c}1966 \\
46 \\
51 \\
45 \\
++ \\
46 \\
56\end{array}$} \\
\hline $\begin{array}{l}2 \\
3 \\
4 \\
5 \\
7 \\
8\end{array}$ & $\begin{array}{l}F \\
M \\
M \\
F \\
F \\
M\end{array}$ & $\begin{array}{r}112 \\
64 \\
136 \\
108 \\
92 \\
81\end{array}$ & $\begin{array}{l}46-64 \\
43-52 \\
42-50 \\
44-50 \\
46-56 \\
44-56\end{array}$ & $\begin{array}{r}83 \\
55 \\
100 \\
84 \\
86\end{array}$ & $\begin{array}{l}48-70 \\
39-42 \\
42 \\
54 \\
\star \\
46-56\end{array}$ & $\begin{array}{l}\frac{80}{76} \\
\frac{80}{\text { Atrial }} \\
\text { fib. }\end{array}$ & $\begin{array}{l}42 \\
48 \\
37 \\
48 \\
\star \\
40\end{array}$ & & & \\
\hline 9 & $\mathbf{M}$ & $86 t$ & $36-42 \dagger$ & 88 & $32-42$ & $-^{\text {no. }}$ & - & $53+$ & 54 & - \\
\hline \multicolumn{2}{|c|}{$\begin{array}{l}\text { Average } \\
\text { Usual range }\end{array}$} & $\begin{array}{l}97 \\
81-112\end{array}$ & $\begin{array}{l}48 \\
42-56\end{array}$ & 82 & $\begin{array}{l}47 \\
42-56\end{array}$ & 79 & $\begin{array}{l}43 \\
40-48\end{array}$ & 52 & $49 \cdot 5$ & 49 \\
\hline
\end{tabular}

* Sinus rhythm, 60-108 with latent heart block. t Figures obtained in 1935 when he was first seen. rate but at least it is more stable and nearer the slower end of the earlier range.

It seems probable that a few of the reported cases of complete heart block in the elderly are congenital cases where the slow heart rate earlier in life has been missed.

Atrial Rate. Originally in our series this averaged 97 a minute, a good deal faster than in normal subjects. In 1955 the average had fallen to 82 and in 1966 to 79 a minute.

Increase of Rate with Exercise. We, like others, found a moderate increase in the ventricular rate after exercise. In four of our patients the average increase was from 48 to 56 a minute in the first minute after exercise. But the return to the resting rate was rapid and if the increase was calculated on only the first quarter minute after exercise, it rose to 64 a minute. The increase in the atrial rate was proportionally greater.

We have repeated these observations in 1965-66 on only two of our patients. In Case 4, the increase was from 37 to 55 a minute, about the same level that was reached in our original observations; but in Case 2 it increased more, from 38 to a rate of $\mathbf{8 5}$ a minute during the first quarter minute. When tested 34 years before, she had shown a greater increase than the other cases, from 46 at rest, to a rate of 76 a minute during the first quarter minute, though only to 59 during the whole of the first minute.

Ikkos and Hanson (1960) found similar fast rates at rest, from 41 to 60 a minute in 11 patients, aged 7 to 23 years. With moderate exercise the average rate increased from 51 to 71 a minute and with more strenuous exercise to 95 a minute. Increases of the same order have been reported after the injection of atropine.
Size of the Heart. When these patients were young (average age, 18 years) their hearts were thought to be a little enlarged. Thus, only 2 had cardiothoracic ratios of 50 or less and the others of between 52 and 55 per cent. These earlier measurements of heart size were nearly all from orthodiagrams, but one of us (M.C.) had extensive experience of this method and thinks his results were reasonably accurate.

Twenty years later, there was no evidence of any enlargement in 4 of the 7 patients. Their hearts were relatively smaller than they had been (mean cardiothoracic ratio 47 instead of $52 \%$ ) when their average age was 14 years. In the other 3, their hearts were still enlarged, about the same size in one (Case 9, the man who died), and larger in another (Case 5) who now had essential hypertension, and in Case 8 with aortic regurgitation (see Table II).

In our recent review there is no further change. The heart of Case 8 is still large but no larger, and on clinical examination this seems to be true for Case 5 also. In the other four (Cases 2, 3, 4, and 7), now between the ages of 46 and 54, there is no change (mean cardiothoracic ratio $47 \%$ ), though in two with hearts of normal size, one seems a little smaller and another a little larger (see Table II and Fig. 3).

Blood Pressure. As might be expected from the large stroke volume, there is generally some increase in the pulse pressure. In 1933, when the average age of our patients was 18 years, the average pulse pressure was $67 \mathrm{~mm}$. $\mathrm{Hg}(142 / 75)$ and in most patients it was not far from $60 \mathrm{~mm}$. $\mathrm{Hg}$, because the average was raised by one patient (Case 5), whose pressure was $190 / 90 \mathrm{~mm}$. $\mathrm{Hg}$ in 1933 . It had risen to $260 / 120$ in 1954 , presumably from essential hypertension. 


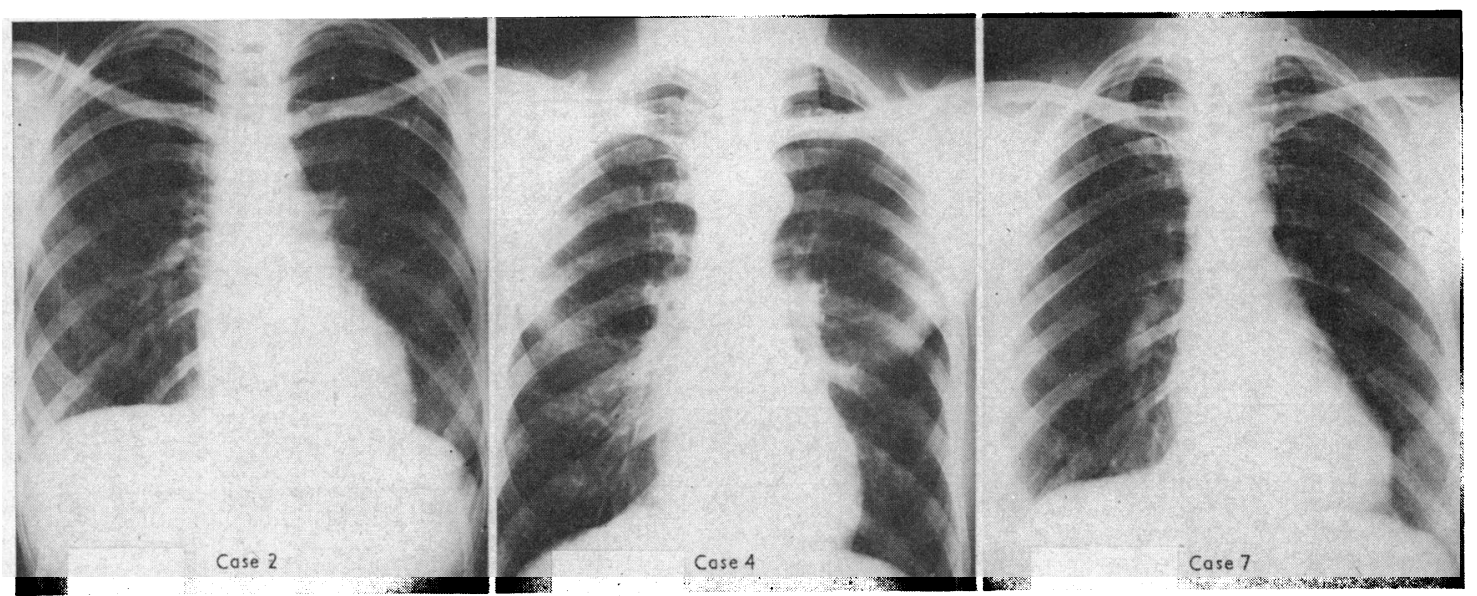

FIG. 3.-Recent $x$-ray films of Cases 2, 4, and 7, with hearts of normal size (cardiothoracic ratio 45 to $47 \%$ ). They were of similar size and shape in 1954 but seemed larger when these three patients were children. Case 3 was much the same as these three. Cases 5 and 8 (Campbell and Thorne, 1956, Fig. 6) have larger hearts, the former because of essential hypertension and the latter because of other malformations (see text).

For comparison, therefore, it seems best to omit Case 5. Without her, the average pulse pressure in 1933 was $62 \mathrm{~mm}$. $\mathrm{Hg}(134 / 72)$. Twenty years later there was hardly any change and it was 61 $\mathrm{mm}$. $\mathrm{Hg}(140 / 79)$. After another ten years it is a little higher, $69 \mathrm{~mm}$. $\mathrm{Hg}(147 / 78)$, but we doubt if the rise is significant as it was mainly due to Case 4 where the figure was a single reading and not a mean of several, as the others were.

\section{Discussion of Circulation in Complete HEART BLOCK}

The lack of co-ordination between the atrial and ventricular contractions must always be some drawback to those with complete heart block. Some evidence of the help that the atrial contraction gives to ventricular filling and cardiac output was put forward many years ago (Gesell, 1916; Wiggers and Katz, 1922) and this is now generally accepted (Gilmore et al., 1963; Samet et al., 1963). Braunwald and Frahm (1961) have, however, shown that it is not as important for those with a healthy myocardium as for those with a damaged one.

The slow ventricular rate is not in itself much disadvantage, for the heart rate is slower in hospital athletes than in their fellow students (Campbell, 1925 ) and in international athletes, especially those making prolonged efforts (Bramwell and Ellis, 1931 ; Beswick and Jordan, 1961; Smith, Cullen, and Thorburn, 1964). Mathewson and Harvie (1957) reported the case of an airman who was one of a group used in a study of the cardiovascular response to strenuous exercise. Because of his slow pulse (c 48) and his freedom from distress he was thought to be one of the more physically fit. Later his slow pulse was shown to be due to complete heart block, probably congenital. He spent ten years in the R.C.A.F., with several years flying as pilot, and had no more tendency than others to experimentally produced blackouts.

The slow rate needs an increase of stroke volume to maintain a normal cardiac output. In adults at least, our figures show no measurable increase of heart size, though the larger stroke volume may increase the total heart volume. Jouve et al. (1966) found the heart enlarged in all their 15 patients but gave no measurements. In 11 of these where hæmodynamic investigations had confirmed the absence of other malformations, they found the right ventricular pressure a little increased, between 30 and $40 \mathrm{~mm}$. $\mathrm{Hg}$ in most of them, and an average gradient across the pulmonary valve of about 11 $\mathrm{mm}$. in nearly half of them, presumably from the larger stroke volume.

Some early investigations by Liljestrand and Zander (1927) help us to understand how our patients have been able to lead a normal, and sometimes a very active, life. With strenuous exercise, a normal man may increase his cardiac output 4 times, roughly by doubling his heart rate and doubling his stroke volume. A well-trained, athletic young man with complete heart block increased his output 3.6 times. He more than doubled his heart rate but because his stroke volume at rest was already 1.75 times the normal (to balance his slow heart rate) he could increase this only another 1.4 times (making in all 2.45 times). More recently, Ikkos and Hanson (1960) found that two girls roughly doubled their cardiac 
output with moderate exercise. One increased the stroke volume by 54 per cent and the ventricular rate by 42 per cent, while the other doubled the rate with little change in the stroke volume. Most patients with other types of complete heart block are not able to increase their heart rate as much as twice, and so become dyspnœic with an exercise less strenuous than this.

This capacity for varying the stroke volume with exercise may not be available in animals where complete heart block has been deliberately produced. Miller et al. (1962) found that in such dogs the heart dilated and hypertrophied to give a larger stroke volume; but when the ventricular rate was increased from 30 to 60 beats a minute, the cardiac output increased proportionally without any further increase in the stroke volume, and if the rate was much faster the stroke volume might fall from insufficient time for ventricular filling.

In general, the cardiac output of patients with artificial pacemakers shows two main types of response (Sowton, 1964). In one, changes in ventricular rate from about 60 to 100 or 110 a minute, with the patient at rest, make little change in the cardiac output, though with maximal exercise the rate is generally near 100 . This type is found more often with a relatively healthy myocardium, and is, therefore, more pertinent to our patients. In the other the cardiac output is maximal at a more fixed rate, generally about 70 to 80 at rest and about the same with exercise, the cardiac output falling sharply with faster ventricular rates. This type of response is found more often in those with a damaged myocardium. Even these patients could generally increase their cardiac output to about twice its resting value (Sowton, 1964).

\section{Notes ON OUR CASES}

Case 2, aged (1)^ 12-52. When 12, her complete heart block at a rate of 50-60 a minute was confirmed at the National Heart Hospital. She complained only of slight breathlessness, possibly because games at school had been forbidden. Her heart seemed slightly enlarged (see Table II) and her pulse pressure was about $80 \mathrm{~mm}$. $\mathrm{Hg}$, wider than in most of the others.

When 19, she was leading a normal life as a shorthand typist, with no complaints except dyspnoea on running.

When 26, she was found to have early tuberculosis of the lung and was off work for eight months. She made a good recovery and married, with medical approval, six months later. When 28 , to the surprise of herself and her friends, she managed all the heavy work of restarting their home after being bombed out.

\footnotetext{
* The figure in brackets shows the age when the slow heart rate was first noted by a doctor. The years of age show the time she was under our observation.
}

When 40 , she looked well and of good physique. She was leading a normal life, though perhaps not able to do quite as much as she would have liked.

Forty years after coming under observation, and now aged 52, she runs her house without help and does some outside voluntary work. She is free from symptoms except that she becomes aware of her heart when tired or worried. Her heart rate, still about 56 in 1954, seems to have settled to $45-40$ a minute, and her cardiogram (Fig. 1) is otherwise normal. Her cardiothoracic ratio has become smaller (Table II and Fig. 3), though the pulse pressure is still $75 \mathrm{~mm}$. and has always been rather wider than in the others (Table I).

Case 3, aged (2)^ 12-47. When 12 , his complete heart block at about 48 a minute was confirmed. His heart seemed slightly enlarged and his pulse pressure was $65 \mathrm{~mm}$. (Table I). He had not been allowed to play games at school, but after this visit started energetic football without any symptoms. Later he worked as an electrician and did much swimming and camping.

When 20, he joined the R.A.F. and was able to do everything with the others. He was passed as fit for flying duties without comment on his heart but was, in fact, kept on his electrical work.

When 35 , he was doing the same work as a civilian. Five years before, he had been found to have fairly severe diabetes that needed dieting and insulin.

$\mathrm{He}$ is now 47 and keeps very well, leading a normal life in every way except for his diabetes which is still well controlled. His heart rate has remained about 48 a minute, his heart is of normal size, and his blood pressure has hardly changed, being $120 / 60-65 \mathrm{~mm}$. $\mathrm{Hg}$ in 1931 and in 1966.

Case 4, aged $(2)^{\star} 12-50$. The only patient with Stokes-Adams attacks. His slow pulse was noted at the age of 2 when he went stiff and blue and lost consciousness while playing on the sands. For the next 2 years he had frequent attacks, up to three a week, but from 4 to 12 years he had only four. The doctor who attended him then had died but he had told the mother that her boy's heart rate was always slow and that this was the cause of the attacks. Apart from them, he had good health and no other symptoms. It may be easier for the reader to follow if his subsequent Stokes-Adams attacks and the treatment he himself adopted are set out here. At 17, a few attacks; changed to easier work for a time. At 24, a few attacks; three weeks in bed and again easier work for a time. At 29, one attack. At 49 , one attack (on Saturday); spent Sunday in bed and resumed work on Monday.

When he was 12 , his complete heart block at a rate of about 45 was confirmed. He looked well and led a normal life at school. At 16, he began work as a baker's vanman but after a time his attacks returned. Without seeing a doctor, he became a hairdresser's assistant, and after a year's freedom from attacks resumed cricket, football, and swimming.

When 18, he chose heavier work, three years in a garage and three years in an aircraft factory, adding fire- 
watching and the Home Guard when the war came. After about a year of these extra duties, when 24, he had a few more Stokes-Adams attacks. After three weeks in bed at home, he found easier work as a machine-shop foreman, still with the Home Guard. A year later, when seen again, he was getting on well but was advised not to overdo things. He had one more attack at the age of 29.

When 37, he looked and felt very well. His heart rate was 42 and his heart seemed normal except for the complete heart block. He was leading an active life as a planning engineer without any recurrence of his attacks.

He remained free from them for 19 years in all, including several years of worrying work in a business of his own. He had sold this and had been working long hours as a driving instructor for a year, when he had another Stokes-Adams attack. He wrote "I went unconscious in bed just before getting up. For the rest of that day I kept feeling at any time I was going out again but I managed to fight it off for that day (Saturday) and with a rest on Sunday I got back to normal again. Since then I have been all right."

He has been re-examined and appears to be well. His heart rate is perhaps a little slower, 37 a minute instead of 42 in 1954; but increases to 55 a minute with gentle exercise. His cardiogram (Fig. 2) still shows complete heart block. His heart is not enlarged (cardiothoracic ratio $45 \%$, Fig. 3). His systolic blood pressure was a little higher (170/80 against $140 / 80 \mathrm{~mm}$. Hg), but this was a single reading since it was difficult to get him to hospital. Now, eight months later, he is 50, and has continued his work without an attack.

Case 5, aged $(2)^{\star} 27-67$. She led a normal life at school and later worked on a farm without symptoms, often cycling 40 miles a day.

When 27, she was seen because of some recent cough and breathlessness, and complete heart block at a rate of about 48 was confirmed. She looked strong and well, but her heart was somewhat enlarged and her blood pressure was about $190 / 90 \mathrm{~mm}$. $\mathrm{Hg}$, higher than in any of the others. Six years later she was very well, but was now doing the housework of the farm and walking two miles a day.

When 42 , she wrote that she had kept well doing the same work, and had found no occasion to see a doctor since her last visit to hospital.

When 56 she was persuaded to see her doctor but would not leave the small village where she had lived all her life. We are greatly indebted to Dr. Murphy for the later information. He found her heart enlarged with a rate of 54 a minute and a blood pressure that had risen to $260 / 120 \mathrm{~mm}$. Hg. She was overweight and sometimes had to stop on hills or stairs because of tightness in the chest and dyspnoa.

In view of these findings, we hardly expected that she would be alive in 1966, but Dr. Murphy kindly went to see her again. She had seen another doctor four years before with some bronchitis and swelling of the ankles. Her ankles were still a little swollen, but she seemed reasonably well, and said that she did all her own housework and that it was fatigue rather than dyspnœea that prevented her walking more than half a mile.

She still had a large heart and the rate at the apex and at the wrist was back to 48 a minute, the same as 40 years before. She had become a rather difficult old lady with a dislike of medical examinations and has refused to have her blood pressure taken.

She is now 67 and, so far as we know, is the oldest patient who has been reported with congenital complete heart block.

Case 7, aged (5)^ 20-54. Her slow heart rate was accepted throughout her school life and at subsequent visits to her doctor. She led a normal life except that school games had been forbidden.

When 20 , she was working as a hairdresser, and was sent to the Heart Hospital because she had been feeling faint and giddy during the previous few months. Her complete heart block, with a rate of about 50, was confirmed. Her pulse pressure was about $60 \mathrm{~mm}$. (the mean of our patients) and her heart was of normal size. Both on the history and on observations on two occasions when she felt faint, her faintness was regarded as vasovagal and in no way suggestive of a Stokes-Adams attack. She resumed work and soon felt well.

From 20 to 23, she attended hospital each 3 months or so and always had a slow heart rate, proved several times to be complete heart block. At three visits she was under close observation for more than an hour and had several electrocardiograms, twice when she felt faint and the third time for us to observe her response to atropine and to exercise: she showed no sudden changes of rate, and then (and on other occasions) several ventricular rates between 43 and 56 a minute were proved to be complete heart block.

From 24 to 35, she attended hospital occasionally, each three years or so. During the war she found her work with an optical firm rather tiring, but needed no treatment. On each occasion she was seen, her slow rate was thought to indicate complete heart block, and this was proved for the last time when she was 35 . For the next 7 years she had no occasion to see a doctor. When 42 , she was asked to come for a routine check of her progress. She felt well and said she was working harder at home than when going out to work. To our surprise, her heart rate was over 100 instead of the usual 46 to 56 a minute. Instead of the usual complete heart block there was sinus tachycardia at 90 a minute with a P-R interval of $0.44 \mathrm{sec}$. She was not aware that any change had taken place. At three other visits during the next four months there was sinus rhythm (70-90 a minute) with P-R intervals between 0.40 and $0.48 \mathrm{sec}$. (see Campbell and Thorne, 1956, Fig. 3 and 4). She said that when at home her pulse was generally between 60 and 70 a minute. Some time between the age of 35 and 42 her heart block had changed from complete to latent.

She is now 54, and leads a normal quiet life, though she is rather tall and stooping and tires easily. Her latent heart block seems now her constant rhythm. Three cardiograms in 1963 and three in 1964-66 have shown heart rates between 78 and 92 with P-R intervals 
between 0.32 and $0.42 \mathrm{sec}$. The last record was taken because she said her heart rate sitting quietly at home was about 60 a minute and we wondered if her complete heart block had returned. No dropped beat has been felt or recorded.

Her heart seemed a little smaller in 1954 than in 1933 and has hardly changed since (cardiothoracic ratio $44 \%$, Fig. 3). Her blood pressure and pulse pressure are a trifle lower than in 1933. It seems a reasonable assumption, though incapable of proof, that she always had complete heart block until she was 35, and that from 42 to 54 she has always had latent heart block without any dropped beats.

Case 8 , aged $(13) \star 13-50$. His complete heart block at a rate of 44-56 was confirmed a few weeks after the slow rate had been observed at school. His blood pressure was $130 / 70 \mathrm{~mm}$. $\mathrm{Hg}$ : Campbell and Suzman (1934) wrote that his heart was enlarged, but this must have been their clinical impression since the cardiothoracic ratio was 49 per cent $(13.9 / 29.3 \mathrm{~cm}$.) in the film reproduced (their Fig. 14).

After leaving school he worked in a bottling factory. When 17 , he was still small but had no symptoms except some dyspnœa playing football.

When 26 years old, he was working hard, though he had been rejected for the army. He was laying concrete floors for $\mathbf{5 4}$ hours a week, and had played football for his club team and won several boxing matches. $\mathrm{He}$ had been regularly at work with no medical attention for 9 years. He had, however, developed left axis deviation with increasing $T$ inversion in lead I (1942).

At 32, he was finding his work difficult, his heart had become larger (cardiothoracic ratio $56 \%$ ), and he now had left bundle-branch block. He had also signs of aortic regurgitation and these were attributed to the presence of a bicuspid aortic valve. He was advised to find easier work and took a tobacconist's shop.

At 38, he was still working a 12-hour day in his shop, but was breathless with the heavier work or when hurrying for a bus. He was overweight and had become bronchitic, so that we were doubtful if all his symptoms were due to his heart. It was moderately enlarged but had not increased further in the last six years (Campbell and Thorne, 1956, Fig. 5 and 6). On radioscopy both ventricles were enlarged: there was no striking vascular pulsation in the lung fields to suggest a significant leftto-right shunt. He still had signs of aortic regurgitation, but his pulse pressure (160/90) was hardly wider than the average in the series.

When he was 48 (1964) he developed orthopnœa at night in addition to his winter bronchitis. A few months later he was admitted to Guy's Hospital under Dr. Scott. A retrograde aortogram and left ventricular angiocardiogram showed that he had corrected transposition of the great trunks, a ventricular septal defect, and mitral and aortic regurgitation.

A year later, he was readmitted with right- and leftsided heart failure. His signs were much the same with a large heart (ratio $56 \%$ ) and an average blood pressure of $163 / 90 \mathrm{~mm}$. Hg. He still had complete heart block, with a rather slower ventricular rate of 38-42 a minute, but had developed atrial fibrillation.

$\mathrm{He}$ is now 50 (1966) and is able to attend the outpatient clinic but still needs treatment with diuretics for his congestive heart failure.

\section{Heart Block with Other Cardiac MALFORMATIONS}

Campbell and Thorne (1956) described 8 additional patients (Cases 12-19) seen in 1948-54, who presented with other malformations of the heart but had heart block also. In 6 of them, there was a ventricular septal defect, often with pulmonary stenosis as well, and in the other 2 there was an atrial septal defect.

Their outlook was thought to be dependent mainly on these other malformations and likely to be less good, and this has proved to be the case. Only 2 are known to have got on well. A girl aged 14 had complete heart block, situs inversus, and probably Fallot's tetralogy, but her disability has been too slight for her to be willing to have any special investigations (Case 13). She has married and adopted a child and has been leading a normal, quiet life for another 15 years. She is the one patient who has behaved in just the same way as most of those who presented with congenital complete heart block as their sole abnormality.

A boy aged 14, with atrial septal defect, was the only patient whose heart block was never complete (Case 18). He showed dropped beats with Wenckebach's periods on each occasion he was seen, and, when he was 18, developed atrial fibrillation. A year later his atrial septal defect was closed successfully, but neither before nor after the operation could sinus rhythm be restored. This was five years ago, and at 24 he is leading a normal active life and is little troubled by the fibrillation.

Four patients are known to have died. In a boy aged 12 , whose heart block was generally complete but sometimes $2: 1$, this did seem to be the main cause of his death. He had acyanotic Fallot's tetralogy, a ventricular septal defect, with pulmonary stenosis too slight to prevent a large left-to-right shunt (Case 14). When he was 20, angiocardiography confirmed the presence of the defect and showed corrected transposition of the great trunks. Two years later, a teflon patch was inserted in his septal defect and the pulmonary stenosis was relieved: the right $A-V$ valve was seen to be bicuspid. But the heart could not be kept beating without electrical stimulation and in spite of the insertion of an artificial pacemaker, it failed to respond and ceased beating the following day.

Three other patients have died, but their deaths did not seem to be greatly influenced by the com- 
plete heart block. None had a necropsy. A boy, aged 12, had transposition of the great trunks (Case 17). A woman, aged 42, had congestive failure with a very large heart and possibly tricuspid atresia (Case 12), and another, aged 35, had failure and Fallot's tetralogy (Case 15). The ages given are those when they were first seen and we could not discover how long their block had been present. Both these women died within three years.

A woman with Eisenmenger's complex (Case 16) returned to Africa when she learnt that nothing could be done. She and a girl with atrial septal defect (Case 19) cannot be traced. Thus, of the 6 patients who have been followed up, 2 are doing well and 4 have died.

\section{SUMMARY}

Six patients with congenital complete heart block have been followed for between 34 and 40 years. They were respectively $12,12,12,13,20$, and 27 years old when first seen by one of us.

Four of them (Cases 2, 3, 4, and 7), now aged between 47 and 54, are leading normal, active lives and have hearts of normal size (average cardiothoracic ratio $47 \%$ ). The only one (Case 4 ) who has ever had a Stokes-Adams attack had them frequently in infancy but only occasionally since, once after an interval of 19 years. Another (Case 7) changed from complete to latent heart block some time between the ages of 35 and 42, and for the past 12 years has had a P-R interval of from 0.32 to $0.48 \mathrm{sec}$. without any observed dropped beats.

The fifth (Case 5) was found to have developed essential hypertension with a blood pressure of $260 / 120 \mathrm{~mm}$. Hg when she was 56, but still manages to run her home at the age of 67 . The sixth (Case 8) had developed a large heart, left bundle-branch block, and some aortic regurgitation by the age of 32; and 16 years later was shown to have corrected transposition, a ventricular septal defect, and mitral and aortic regurgitation. Now aged 50 , he needs treatment for his congestive heart failure.

Of 8 other patients seen in 1948-54 with various cardiac malformations as well as heart block, which may or may not have been congenital, 6 have been traced. They have not got on nearly as well as the previous group. Only 2 are doing well and 4 have died during a few years follow-up.

When complete heart block is congenital, the rate is faster, generally over 40 a minute, and can be increased more with exercise than when the block is acquired. There is some evidence that the stroke volume also can be increased with exercise more effectively.

A patient with congenital complete heart block and no other abnormality should be allowed to lead a normal life, including strenuous occupations or games when so desired.

We are very grateful to Dr. Murphy of Bicester for visiting Case 5 in 1954 and again in 1965-66 and for writing to us about her. We should like to thank Dr. Watt of Basingstoke for further details about Case 3, Dr. Gover of St. Leonards for a final electrocardiogram of Case 7 when she had left London and wrote that her heart had become slower, and Dr. Scott and Dr. Deuchar under whose care Case 8 has now passed.

\section{REFERENCES}

Beswick, F. W., and Jordan, R. C. (1961). Cardiological observations at the sixth British Empire and Commonwealth Games. Brit. Heart f., 23, 113.

Bramwell, C., and Ellis, R. (1931). Some observations on the circulatory mechanism in Marathon runners. Quart. f. Med., 24, 329.

Braunwald, E., and Frahm, C. J. (1961). Studies on Starling's law of the heart. IV. Observations on the hemodynamic functions of the left atrium in man. Circulation, 24, 633 .

Campbell, M. (1925). Weight, vital capacity, pulse rate before and after exercise, and physical fitness in health. Guy's Hosp. Rep., 75, 263.

- (1942). Partial heart block due to digitalis. Brit. Heart F., 4, 131.

- (1943a). Congenital complete heart block. Brit. Heart $\mathfrak{F}, \mathbf{5}, 15$.

- (1943b). Partial heart block with dropped beats. Brit. Heart f., 5, 55.

- (1943c). Latent heart block. Brit. Heart F., 5, 163.

- (1944). Complete heart block. Brit. Heart f., 6, 69.

-, and Suzman, S. S. (1934). Congenital complete heart-block. An account of eight cases. Amer. Heart F., 9, 304.

—, and Thorne, M. G. (1956). Congenital heart block. Brit. Heart f., 18, 90.

Gesell, R. A. (1916). Cardiodynamics in heart block as affected by auricular systole, auricular fibrillation and stimulation of the vagus nerve. Amer. F. Physiol., 40, 267.

Gilmore, J. P., Sarnoff, S. J., Mitchell, J. H., and Linden, R. J. (1963). Synchronicity of ventricular contraction: observations comparing hæmodynamic effects of atrial and ventricular pacing. Brit. Heart f., 25, 299.

Ikkos, D., and Hanson, J. S. (1960). Response to exercise in congenital complete atrioventricular block. Circulation, 22, 583.

Jouve, A., Gerard, R., Torresani, J., and Arnoux, M. (1966). Les blocs auriculo-ventriculaires congénitaux complets. Mal. cardiovasc., 7, 271.

Liljestrand, A., and Zander, E. (1927). Studies of the work of the heart. during rest and muscular activity in a case of uncomplicated total heart-block. Acta med. scand., 66, 501.

Mathewson, F. A. L., and Brereton, D. C. (1964). Atrioventricular heart block: University of Manitoba followup study reports-series 1963. Trans. Ass. Life Insur. med. Dir. Amer., 48, 210.

- , and Harvie, F. H. (1957). Complete heart block in an experienced pilot. Brit. Heart F., 19, 253.

Miller, D. E., Gleason, W. L., Whalen, R. E., Morris, J. J., and McIntosh, H. D. (1962). Effect of ventricular rate 
on the cardiac output in the dog with chronic heart block. Circulat. Res., 10, 658.

Samet, P., Jacobs, W., Bernstein, W. H., and Shane, R. (1963). Hemodynamic sequelæ of idioventricular pacemaking in complete heart block. Amer. F. Cardiol., 11, 594.

Smith, W. G., Cullen, K. J., and Thorburn, I. O. (1964). Electrocardiograms of marathon runners in 1962 Commonwealth Games. Brit. Heart f., 26, 469.

Sowton, E. (1964). Hæmodynamic studies in patients with artificial pacemakers. Brit. Heart.f., 26, 737.
White, P. D. (1951). Heart Disease, 4th ed. Macmillan, New York.

Wiggers, C. J., and Katz, L. N. (1922). Contour of ventricular volume curves under different conditions. Amer. F. Physiol., 58, 439.

Wood, P. (1956). Diseases of the Heart and Circulation, 2nd ed. Eyre and Spottiswoode, London.

Zoob, M., and Smith, K. S. (1963). The ætiology of complete heart-block. Brit. med. F., 2, 1149. 